\begin{tabular}{|l|l|l|}
\hline \multicolumn{2}{|c|}{ PublisherInfo } \\
\hline \hline PublisherName & $:$ & BioMed Central \\
\hline \hline PublisherLocation & $:$ & London \\
\hline \hline PublisherImprintName & $:$ & BioMed Central \\
\hline \hline
\end{tabular}

\title{
Low HLA-DM expression in RA
}

\begin{tabular}{|l|l|l||}
\hline \multicolumn{2}{|c||}{ ArticleInfo } \\
\hline \hline ArticleID & $:$ & 109 \\
\hline \hline ArticleDOI & $:$ & $10.1186 /$ ar-2001-66885 \\
\hline \hline ArticleCitationID & $:$ & 66885 \\
\hline \hline ArticleSequenceNumber & $:$ & 66 \\
\hline \hline ArticleCategory & $:$ & Paper Report \\
\hline ArticleFirstPage & $:$ & 1 \\
\hline \hline ArticleLastPage & $:$ & 3 \\
\hline \hline & & RegistrationDate : 2001-2-20 \\
\hline ArticleHistory & $:$ & OnlineDate \\
\hline \hline ArticleCopyright & $:$ & Biomed Central Ltd2001-2-20 \\
\hline \hline ArticleGrants & $:$ & \\
\hline \hline ArticleContext & $:$ & 130753311 \\
\hline \hline
\end{tabular}


Robert Busch, ${ }^{\text {Affl }}$

Affl Stanford University Medical Center, Stanford, CA, USA

\section{Keywords}

Antigen processing/presentation, HLA-disease association, HLA-DM, promoter polymorphism, HLAdisease association, HLA-DM, promoter polymorphism, HLA-disease association, HLA-DM, promoter polymorphism, HLA-disease association, HLA-DM, promoter polymorphism, HLA-disease association, HLA-DM, promoter polymorphism

\section{Context}

Several MHC class II (MHC-II) alleles, e.g. HLA-DRB1*0401, are associated with severe rheumatoid arthritis (RA). The relevant polymorphisms map to the antigen binding groove, but unique arthritogenic peptides have not been identified. In antigen presenting cells, peptide loading by MHC class II is facilitated by HLA-DM, an MHC-II chaperone and peptide exchange catalyst. Generally, expression of DM (DMA/DMB) genes and of MHC-II is co-regulated, but distinct promoter regions allow for some differential regulation. In some studies, structural polymorphisms in DM have also been associated with RA in a small subset of patients. Study aims were to identify and functionally characterize polymorphisms in the DMA and DMB promoters, and to compare DM levels in RA patients and controls.

\section{Significant findings}

One rare dimorphism in the DMA and two in the DMB promoter were found; each was associated with DM structural polymorphisms, but none were associated with RA. The rare DMB-168T genotype decreased constitutive promoter activity in a B cell line; this nucleotide is part of an NF-?B site, but no differences in NF-?B p50 binding was seen. Both DMB promoter polymorphisms diminished interferon (IFN)-?-induced gene expression; the DMA polymorphism had no detectable impact. Steady state levels of DMA and DMB mRNA were reduced by about threefold in peripheral blood B cells of RA patients. Patients with ankylosing spondylitis, in contrast, had normal or slightly reduced DM mRNA levels. Steady-state levels of DM protein also appeared low in RA.

\section{Comments}


The key finding was that expression of DM, but not DR, is decreased in RA but not control B cells. This is not due to promoter polymorphisms, whose functional impact in vivo remains unclear. Instead, it may relate to shifts in B cell subpopulations in RA, to differential promoter occupancy with DM-specific transcription factors, or to differences in DM message stability. Sample size was small in the expression studies, so work in larger, diverse patient cohorts is needed. The effects of immunosuppressive drugs and disease duration also warrant examination. Whether low DM expression is a cause or a consequence of immune dysfunction in RA also remains unclear. DM expression defects would diminish the efficiency of MHC-II peptide editing and chaperoning; this could reduce the density and change the identity of peptides bound to disease-associated MHC-II alleles during thymic selection or induction of autoimmunity. A role for low DM expression in RA etiology thus seems plausible.

\section{Methods}

Genomic sequencing, reporter gene assay, EMSA, RT-PCR, western blotting

\section{Additional information}

Pinet V, Combe B, Avinens O, Caillat-Zucman S, Sany J, Clot J, Eliaou JF: Polymorphism of the HLA-DMA and DMB genes in rheumatoid arthritis. Arthritis Rheum 1997, 40:854-858

(PubMedabstract).

Walter W, Scheuer C, Loos M, Reichert TE, Maeurer MJ: H2-M?1 or H2-M?2 heterodimers equally promote CLIP removal in I-A q molecules from autoimmune-prone DBA/1 mice. $J$ Biol Chem 2001, accepted for publication (PubMedabstract).

\section{References}

1. Louis-Plence P, Kerlan-Candon S, Morel J, Combe B, Clot J, Pinet V, Eliaou J-F: The downregulation of HLA-DM gene expression in rheumatoid arthritis is not related to their promoter polymorphism. J Immunol. 2001, 165: 4861-4869.

This PDF file was created after publication. 